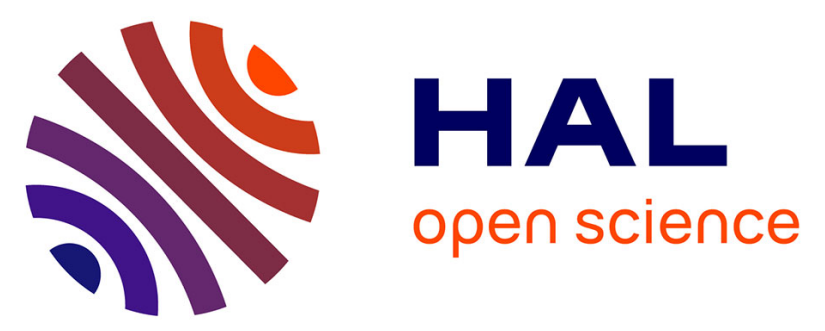

\title{
Fluorodynamers Displaying Tunable Fluorescence on Constitutional Exchanges in Solution and at Solid Film-Solution Interface
}

Mingran Si, Weijia y Zhu, Yan Zhang, Mihail Barboiu, Jinghua Chen

\section{- To cite this version:}

Mingran Si, Weijia y Zhu, Yan Zhang, Mihail Barboiu, Jinghua Chen. Fluorodynamers Displaying Tunable Fluorescence on Constitutional Exchanges in Solution and at Solid Film-Solution Interface. Chemistry - A European Journal, 2020, 26, pp.10191 - 10194. 10.1002/chem.202000981 . hal-03028973

\section{HAL Id: hal-03028973 \\ https://hal.science/hal-03028973}

Submitted on 30 Nov 2020

HAL is a multi-disciplinary open access archive for the deposit and dissemination of scientific research documents, whether they are published or not. The documents may come from teaching and research institutions in France or abroad, or from public or private research centers.
L'archive ouverte pluridisciplinaire HAL, est destinée au dépôt et à la diffusion de documents scientifiques de niveau recherche, publiés ou non, émanant des établissements d'enseignement et de recherche français ou étrangers, des laboratoires publics ou privés. 


\title{
Fluorodynamers displaying tunable fluorescence on constitutional exchanges in solution and at solid film-solution interface
}

\author{
Mingran Si, ${ }^{[a]}$ Weijia Zhu, ${ }^{[a]}$ Yan Zhang, ${ }^{*[a]}$ Mihail Barboiu*[b] and Jinghua Chen ${ }^{*[a]}$
}

\author{
[a] M. Si, W. Zhu, Prof. Y. Zhang, Prof. J. Chen \\ Jiangnan University \\ 1800 Lihu Avenue, Wuxi, 214122, P.R. China \\ E-mail: zhangyanyz@jiangnan.edu.cn; chenjinghua@jiangnan.edu.cn \\ [b] Dr. M. Barboiu \\ Institut Europeen des Membranes, Adaptive Supramolecular Nanosystems Group \\ University of Montpellier, ENSCM-CNRS \\ Place E. Bataillon CC047, Montpellier, F-34095, France \\ E-mail: mihail-dumitru.barboiu@umontpellier.fr
}

Key Laboratory of Carbohydrate Chemistry and Biotechnology, Ministry of Education, School of Pharmaceutical Sciences

Supporting information for this article is given via a link at the end of the document.

\begin{abstract}
Dynamic covalent polymers -the dynamers- are adaptive materials that offer timely variant adaptive macroscopic organization across extended scales. In the current study, imine exchange reactions and fluorescence transfer can occur at the interfaces between various solutions and solid state dynameric films. The fluorescence quenching upon imine formations for designed fluorogen was successfully demonstrated, and this tunable fluorescence was further used to study the re-composition of a solid film. Moreover, the dynamic covalent films also exhibited responsiveness to competing amines and acid/base conditions, both in solutions and solid filmsolution interface. This work can provide more insights into interface dynamic chemistry and hold great potentials for further applications in optical and biomedical materials.
\end{abstract}

Dynamic constitutional chemistry and its subfield dynamic covalent chemistry have been continuously developed during the last two decades. ${ }^{[1]}$ The accumulated achievements have led to enriched diversities in reaction types, ${ }^{[2]}$ intricate architectures, ${ }^{[3]}$ advanced properties $^{[4]}$ and the increasingly expanded applications, varying from chemical/enzymatic catalysis ${ }^{[5]}$ to biomimetic signal transfer ${ }^{[6]}$ to adaptive smart materials. ${ }^{[7]}$ Among all these advances, diverse reversible covalent reactions have been explored ${ }^{[8]}$ and the arrangement of dynamic networks has been diversified, ${ }^{[9]}$ providing adaptive systems with higher complexity and multiple responsiveness.

More recently, dynamic chemistry on interfaces has emerged as a new research topic. Studies about dynamic covalent reactions between liquid-solid, ${ }^{[10]}$ liquid-liquid, ${ }^{[11]}$ liquidair $^{[12]}$ and solid-solid ${ }^{[13]}$ interfaces have been illustrated. One direct proof of component exchanges on solid-solid interface is the selfhealing ${ }^{[7 a, 14]}$ or optical ${ }^{[13 a, b]}$ properties of the dynamers, indicating the breaking down and reconnection of the reversible covalent bonds through the interface. Furthermore, there are a few direct observations of the constitutional exchanges between solid-liquid interfaces, when sophisticated 2D structures are detected by scanning tunneling microscopy (STM). ${ }^{[10 b]}$

Fluorescent probes with high sensitivity and selectivity are frequently used in dynamic systems, mostly related to imaging of protein interactions, drug delivery processes, ion-metal sensing, etc. ${ }^{[15]}$ There are also studies using fluorescent probes in dynamic covalent systems to indicate the switch of molecular bonds or change of assembly states in solution between various target entities. ${ }^{[16]}$ For example, the formation of imine bonds can usually result in the switch off the emission of amine functionalized fluorogens, leading to in situ observation of dynamic reactions in solution via ligand displacement assays ${ }^{[17]}$ or in solid films of optodynamers. ${ }^{[13,18]}$

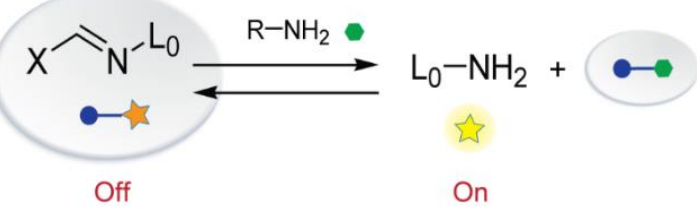

Figure 1. Schematic illustration of the imine exchange concept with fluorescence tuning.

In the current study, to set up the dynamic covalent exchanging fluorodynamer, fluorogenic amine 4-(1H-Phenanthro $[9,10-d]$ imidazol-2-yl)benzenamine, L0 was chosen as the core structure. The synthesis of LO was through two steps: ${ }^{[19]}$ first, a condensation reaction between phenanthrene-9,10-dione, 4nitrobenzaldehyde and ammonium acetate, followed by reduction of the nitro group, providing $\mathbf{L} 0$ as a yellow powder (yield $67 \%$ ). Using dimethyl sulphoxide (DMSO) as the solvent and $350 \mathrm{~nm}$ as the excitation wavelength, L0 exhibited a fluorescence emission band with a maximum at $\lambda_{\mathrm{em}} 452 \mathrm{~nm}$, associated with the $\pi-\pi^{*}$ transition from the phenanthrene moiety. Subsequently, the reaction between the fluorogenic amine LO and 3pyridinecarboxaldehyde 1 was performed in methanol for $24 \mathrm{~h}$ at $60{ }^{\circ} \mathrm{C}$, yielding $88 \%$ formation of imine product L1 (Figure 2a). Under the same excitation conditions, the emission intensity of L1 in methanol was decreased $~ 80 \%$ compared to LO (Figure $2 b$ ), indicating the quenching of fluorescence by transforming amine LO to imine L1. This can be explained by photoisomerization of the imine bond, which accelerated non-radiative transition of the activated state of the imine molecules. ${ }^{[20]}$ Moreover, there is a small shift of the emission peak from $452 \mathrm{~nm}$ (green line in Figure 
2b) of $\mathbf{L} \mathbf{0}$ to $449 \mathrm{~nm}$ of $\mathbf{L 1}$, owing to the change of electron density of the phenanthrene fluorogen after the addition of imine double bonds. ${ }^{[16 a]}$ The addition of $\mathrm{HCl}$ to a methanolic solution of $\mathbf{L 1}$ results in the imine-bond hydrolysis and an immediate recovery of the fluorescence intensity $\left(\lambda_{\mathrm{ex}} 350 \mathrm{~nm}, \lambda_{\mathrm{em}} 452 \mathrm{~nm}\right)$ to over $85 \%$ of the original value of LO (Figure $2 \mathrm{c}$ ). Subsequently, the addition of $\mathrm{NaOH}$ allow to decrease the fluorescence intensity $\left(\lambda_{\mathrm{ex}} 350 \mathrm{~nm}\right.$, $\lambda_{\mathrm{em}} 452 \mathrm{~nm}$ ) to a substantial extent after $24 \mathrm{~h}$, reflecting the gradual reformation of imine bond. The slightly higher fluorescence intensity of the final mixture than L1 can be contributed to the decreased available aldehyde 1 from the promoted aldol reaction in such basic condition, making it difficult to be completely converted to imine $\mathbf{L 1}$ again.

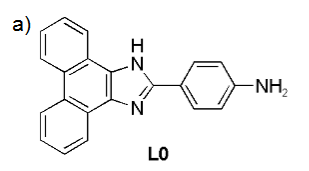

b)

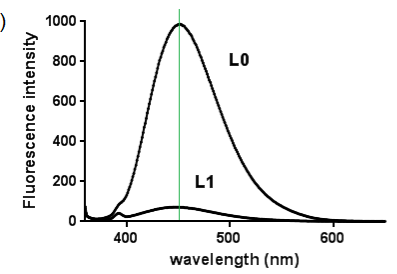

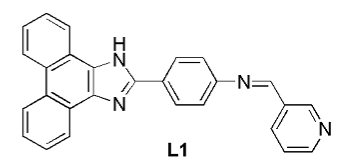

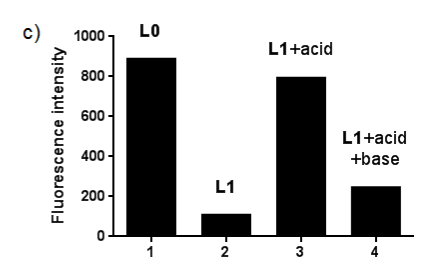

Figure 2. a) Imine formation reaction from fluorescent amine $\mathbf{L} \mathbf{0}$ and aldehyde 1; b) fluorescent spectroscopy of L0 and L1 (under $\lambda$ ex $350 \mathrm{~nm}$ ); c) the fluorescent intensity changes of $\mathbf{L} \mathbf{1}$ subjected to acid and base treatments.

Another approach to tune of the fluorescence of $\mathbf{L 1}$ through dynamic imine bonds can be realized by the addition of a second amine. Thereafter, the imine exchange reaction was optimized by using different amounts of aniline (2) in $\mathrm{MeOH}$ at room temperature. The results showed that the increased amounts of 2 obviously raised the conversions and a L1 : amine $=1: 4$ molar ratio has been selected (Table S1, Figure S10a). Then, $\mathrm{MeOH}$, $\mathrm{H}_{2} \mathrm{O}$, EtOH and $\mathrm{PrOH}$ solvents were evaluated, among which, $\mathrm{MeOH}$ provided the highest conversion (60\%) after $24 \mathrm{~h}$, followed by $\mathrm{EtOH}(11 \%)$ and $\mathrm{PrOH}(8 \%)$, while $\mathrm{H}_{2} \mathrm{O}$ only gave trace amount of product under the same conditions due to the poor solubility of LO (Figure S10b). On the other hand, elevated temperatures (up to $60{ }^{\circ} \mathrm{C}$ ) and increased concentration of LO (from $0.8 \mathrm{mM}$ to $4.8 \mathrm{mM}$ ) led to only a bit higher (<10\%) reaction conversions (Figure S10c-d), so room temperature and $1.6 \mathrm{mM}$ was chosen for operational convenience.

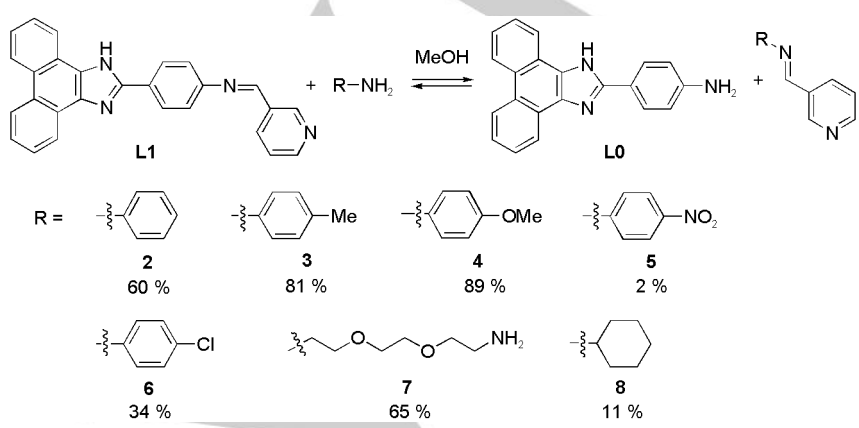

Figure 3. Imine exchange reactions between L1 and various amines with the indicated conversions, measured after $24 \mathrm{~h}$ with fluorescence spectroscopy.
With the optimized imine exchange condition in hand, other amines were examined, including substituted anilines, such as $p$ toluidine (3), 4-methoxyaniline (4), 4-nitroaniline (5) and 4chloroaniline (6) or aliphatic linear 2,2-(ethylenedioxy) bis(ethylamine) (7) and cyclic cyclohexylamine (8) (Figure 3). Among the various substituted anilines, it was apparent that the presence of electron-donating groups accelerated the exchange reaction, resulting in the higher formation of imines P3 (81\%) and P4 (89 \%) after $24 \mathrm{~h}$, comparing to the P2 (60\%). Oppositely, the amines substituted with electron-withdrawing groups showed much lower conversions after 24 h, to P5 (2\%) and to P6 (34\%). Besides, a high reactivity was observed for the double amine substituted compound 7, leading to the imine P7 (65\%), and a low conversion to P8 (11\%) was observed for the sterically hindered cyclic structure of amine 8 .

After establishing the fluorescent switch system tuned by dynamic imine chemistry in solution, the fluorescence on/off mechanism was applied to fluorodynameric species in solution and at the solid film-liquid interfaces. First, a fluorodynamer was prepared by connecting 1,3,5-benzenetricarbaldehyde (9), diamine 7 and fluorogenic amine LO (molar ratio 1:1.4:0.2) through imine formation reaction (Figure 4a), occurring in $\mathrm{MeOH}$ for $10 \mathrm{~min}$ at room temperature. The solution was poured then into a Teflon mode $(2 \mathrm{~cm} \times 2 \mathrm{~cm})$ and the solvent was evaporated at room temperature, yielding a yellow thin film. Infrared spectroscopy was subsequently used to analyse the film. After the reaction, the aldehyde peak at $1694 \mathrm{~cm}^{-1}$ (marked as a green line) from 9 diminished, meanwhile, a new peak appeared at $1643 \mathrm{~cm}$ 1 (Figure 4b), indicating the consumption of all the aldehyde groups and the formation of imine bonds. Furthermore, the film surface morphology was obtained from scanning electron microscopy (SEM), while porous structures containing microsized particles with diameter around $2 \mu \mathrm{m}$ were observed (Figure 4c), which may come as previously observed, ${ }^{[21]}$ from hydrophobic/hydrophilic phase segregation during the film formation. Derivative thermogravimetric analysis (DTG) and differential scanning calorimetry (DSC) showed good thermostability up to $\sim 300{ }^{\circ} \mathrm{C}$ of the fluorodynamer (Figure S12S13).
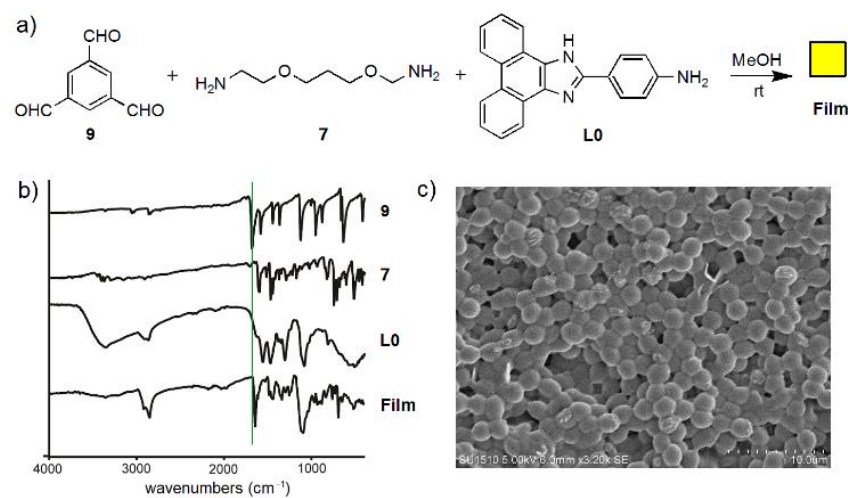

Figure 4. a) Preparation of the fluorodynameric film from trialdehyde 9, diamine linker $\mathbf{7}$ and fluorescent amine L0; b) Infrared (IR) spectroscopy of the film compared to individual starting components; c) Scanning electron microscopy (SEM) image of the film surface.

The fluorodynameric film was next subjected for imine exchange reactions between the solid film-amine solution interfaces. The imine bonds inside the solid film with quenched fluorescence can 
be replaced by another amine in solution and release the free amine L0, turning on the fluorescence. As the competing amines, aniline or its substituted derivatives were included in the $\mathrm{MeOH}$ solution, in which the film was also immersed. After certain time intervals, $5 \mu \mathrm{l}$ of each solution was retrieved for analysis of fluorescent intensity, which can be subsequently transformed into the concentration of free $\mathbf{L} \mathbf{0}$ and reaction conversions. From the time-course analysis, typical exponential curves were obtained for most of the exchange reactions (Figure 5), indicating first order kinetics. Compared to aniline, substitution of electron-donating groups, such as methyl- aniline (3) and methoxyl- aniline (4), can not only accelerate the initial reaction rates of imine exchange, but also contribute to the formation of new imine bonds, leading to higher percentages of released $\mathbf{L O}$ in solution: $33 \%$ for amine 4 and $25 \%$ for amine 3, comparing to $18 \%$ for aniline 2 after 3 days. On the other hand, the electron-withdrawing group in $p$ chloro-aniline (6) decreased the final concentration of free $\mathbf{L} \mathbf{0}$ to $15 \%$, while $p$-nitro-substituted aniline (5) showed very slow reaction rates, without reaching the equilibrium even after 20 days. This trend was in consistence with their individual reactivity of the aromatic amines, where the nucleophilic attack ability of amines was promoted or weakened by the electron distribution of the neighbouring aromatic ring.
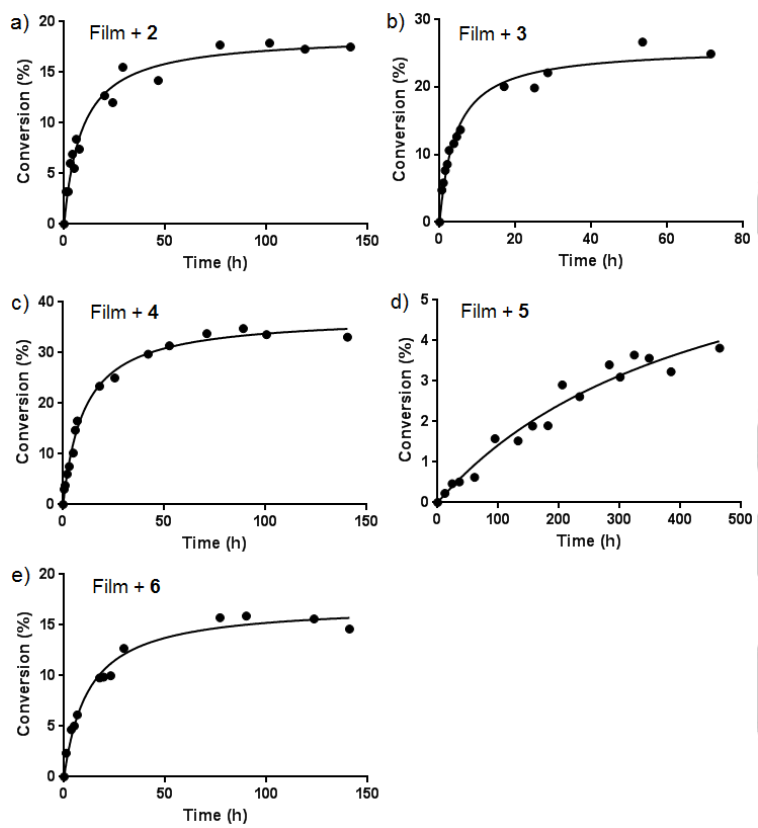

Figure 5. The time-course analyses of the progress of the imine exchange reaction between the solid-solution interfaces, monitored by fluorescent spectroscopy, fitted by non-linear regression analysis. The reactions were performed with the solid film in $\mathrm{MeOH}$ with 4 eq. of competing amines 2-6.

As a reference, the competing amine/imine fluorodynamer exchanges were examined in solution. For all tested amines, both the reactivity and the final reached equilibrium were higher than the case in solid film-solution interfaces (Figure S16). For instance, the highest conversion was achieved for 4-methoxyaniline (4) (89\%), comparing to $33 \%$ on solid-solution interfaces. This can probably be explained by the physical barrier presented from the solid film, demanding extra film-diffusion for all the amines. Furthermore, not surprisingly, the same reactivity trend among variously substituted electron-donating/withdrawing groups was observed as in solution.

The fluorescence properties can be examined by the confocal microscopy in solid state. The LO powder alone gave blue emission light, induced by $\lambda_{\mathrm{ex}} 405 \mathrm{~nm}$, which was in consistence with previous reports. ${ }^{20}$ After forming the film through covalent imine bonds, the blue light was mostly disappeared and replaced by green emission under $\lambda_{\mathrm{ex}} 488 \mathrm{~nm}$ (Figure 6a). Moreover, a film that was reacted with aniline 2 in $\mathrm{MeOH}$ for $4 \mathrm{~h}$ was also measured by confocal microscopy. As a result, with the mixed excitation of $\lambda_{\text {ex }} 405 \mathrm{~nm}$ and $\lambda_{\text {ex }} 488 \mathrm{~nm}$, there were more blue spots emerged on the edge of the film while the green emission was clearly weakened (Figure 6b), indicating the release of the free amine LO during the solid film-solution imine exchange processes. a)

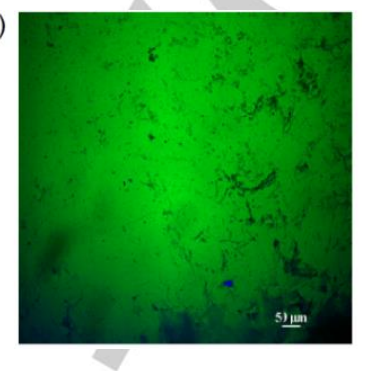

b)

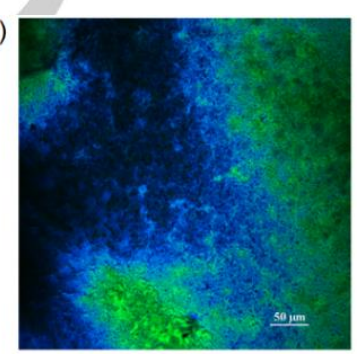

Figure 6 . The images of a) the original film and b) the film edge after reacting with aniline for $4 \mathrm{~h}$, obtained by confocal microscopy, under the excitations of both $405 \mathrm{~nm}$ and $488 \mathrm{~nm}$. The green emission light represents the imine film (under $\lambda$ ex $488 \mathrm{~nm}$ ), while the blue emission light corresponds to the free amine LO (under $\lambda$ ex $405 \mathrm{~nm}$ ).

In summary, we have designed a fluorodynameric system based on dynamic covalent bonds, and examined its uses in direct observation of the imine exchange processes in solution and between solid film-solution interfaces. The fluorogen LO used here can be quenched after forming imine bonds with aldehyde 1 and present acid/base fluorescence on/off responsiveness. The fluorogen L0 was further embedded through imine formation in dynameric networks, which were able to perform imine exchanges in response to external amines effectors in solution and at the interface solid film-solution. These results showed that the exchange rates were highly influenced by the substituents on the competing exchanging amines. In all cases, LO was successfully released from the solid film, with slower rates than the exchanges in solution, as monitored by both fluorescence spectroscopy and confocal microscopy results. These features have promising potential for its implementation in optical materials for adaptive sensing or photoactive devices responding to external stimuli. The dynamic exchanges described here, emphasized the important opportunities offered by the application of the principles of constitutional dynamic chemistry to materials science.

\section{Acknowledgements}

The study was in part supported by the Natural Science Foundation of Jiangsu Province (BK20180625), the National First-class Discipline Program of Light Industry Technology and 
Engineering (LITE2018-20), and Fundamental Research Funds for the Central Universities (JUSRP51709A).

Keywords: Dynamic polymers • Imine • Fluorescence • Films • Interface reactions

[1] a) W. Zhang and Y. Jin, Dynamic Covalent Chemistry: Principles, Reactions, and Applications, John Wiley \& Sons Ltd. 2017; b) M. Barboiu Constitutional Dynamic Chemistry, Springer-Verlag Berlin, Heidelberg, 2012; c) O. Ramström, J.-M. Lehn, Nat. Rev. Drug Discov. 2002, 1, 26 36; d) B.L. Miller, Dynamic Combinatorial Chemistry: in Drug Discovery, Bioorganic Chemistry and Materials Science, John Wiley and Sons Ltd. 2010; e) J. N.H. Reek, S.Otto, Dynamic Combinatorial Chemistry, WileyVCH: Weinheim, 2010.

[2] a) W.J. Ong and T.M. Swager, Nat. Chem., 2018, 10, 1023-1030; b) P.R. Christensen, A.M. Scheuermann, K.E. Loeffler and B.A. Helms, Nat Chem., 2019, 11, 442-448.

[3] L. Shen, N. Cao, L. Tong, X. Zhang, G. Wu, T. Jiao, Q. Yin, J. Zhu, Y. Pan and H. Li, Angew. Chem. Int. Ed., 2018, 57, 16486-16490.

[4] a) H. Sun, C. P. Kabb, M.B. Sims and B.S. Sumerlin, Prog. Polym. Sci., 2019, 89, 61-75; b) G. Zhang, W. Peng, J. Wu, Q. Zhao and T. Xie, Nat Commun., 2018, 9, 4002

[5] a) Y. Zhang, Y.-M. Legrand, E. Petit, C.T. Supuran and M. Barboiu, Chem. Commun., 2016, 52, 4053-4055; b) F. Schaufelberger and O. Ramström, J. Am. Chem. Soc., 2016, 138, 7836-7839.

[6] a) Y. Ren and L. You, J. Am. Chem. Soc., 2015, 137, 14220-14228; b) Y. Cheng, L. Zong, J. López-Andarias, E. Bartolami, Y. Okamoto, T.R Ward, N. Sakai and S. Matile, Angew. Chem. Int. Ed., 2019, 58, 95229526.

[7] a) N. Roy, B. Bruchmann and J.-M. Lehn, Chem. Soc. Rev., 2015, 44, 3786-3807; b) R.J. Wojtecki, M.A. Meador and S.J. Rowan, Nat. Mater., 2011, 10, 14-27.

[8] a) S. Debnath, R.R. Ujjwal and U. Ojha, Macromolecules, 2018, 51, 9961-9973; b) Y. Yi, H. Xu, L. Wang, W. Cao and X. Zhang, Chem. Eur. J., 2013, 19, 9506-9510.

[9] a) Y. Zhang, P. Vongvilai, M. Sakulsombat, A. Fischer and O. Ramström, Adv. Synth. Catal., 2014, 356, 987-992; b) Y. Zhang, L. Hu and O. Ramström, Chem. Commun., 2013, 49, 1805-1807; c) Y. Zhang and O. Ramström, Chem. Eur. J., 2014, 20, 3288-3291.

[10] a) M. Aiba, T. Higashihara, M. Ashizawa, H. Otsuka and H. Matsumoto, Macromolecules, 2016, 49, 2153-2161; b) A. Ciesielski, M. El Garah, S Haar, P. Kovaříček, J.-M. Lehn and P. Samorì, Nat. Chem., 2014, 6 1017-1023; c) Y. Yu, J. Lin and S. Lei, RSC Adv., 2017, 7, 11496-11502; d) L. Tauk, A.P. Schröder, G. Decher and N. Giuseppone, Nat. Chem. 2009, 1, 649-656.

[11] a) G. Ren, L. Wang, Q. Chen, Z. Xu, J. Xu and D. Sun, Langmuir, 2017, 33, 3040-3046; b) C. A. Zentner, F. Anson, S. Thayumanavan and T.M Swager, J. Am. Chem. Soc., 2019, 141, 18048-18055.

[12] W. Dai, F. Shao, J. Szczerbiński, R. McCaffrey, R. Zenobi, Y. Jin, A.D. Schlüter and W. Zhang, Angew. Chem. Int. Ed., 2016, 55, 213-217.

[13] a) T. Ono, S. Fujii, T. Nobori, J.-M. Lehn, Chem. Commun. 2007, 43604362; b) L. Marin, B.C. Simionescu, M. Barboiu, Chem. Commun. 2012 48, 8778-8780; c) G. Deng, Q. Ma, H. Yu, Y. Zhang, Z. Yan, F. Liu, C. Liu, H. Jiang and Y. Chen, ACS Macro Lett., 2015, 4, 467-471.

[14] K.K. Oehlenschlaeger, J.O. Mueller, J. Brandt, S. Hilf, A. Lederer, M. Wilhelm, R. Graf, M.L. Coote, F.G. Schmidt and C. Barner-Kowollik, Adv. Mater., 2014, 26, 3561-3566.

[15] a) S. Ding, Y. Che, Y. Yu, L. Liu, D. Jia and J. Zhao, J. Org. Chem., 2019, 84, 6752-6756; b) Y. Hou, S. Li, Z. Zhang, L. Chen and M. Zhang, Polym Chem., 2020, 11, 254-258; c) H. Zhao, K. Peng, F. Lv, L. Liu and S. Wang, ACS Appl. Bio Mater., 2019, 2, 1787-1791.

[16] a) H. Zou, Y. Hai, H. Ye and L. You, J. Am. Chem. Soc., 2019, 141, 16344-16353; b) F. Zaubitzer, T. Riis-Johannessen and K. Severin, Org Biomol. Chem., 2009, 7, 4598-4603.

[17] a) B.T. Nguyen and E.V. Anslyn, Coord. Chem. Rev. 2006, 250, 31183127. b) X. Sun, B. M. Chapin, P. Metola, B. Collins, B. Wang, T.D.
James and E.V. Anslyn, Nat. Chem. 2019, 11, 768-778 c) N. McGregor, C. Pardin and W.G. Skene, Aust. J. Chem., 2011, 64, 1438-1446.

[18] a) N. Giuseppone, G. Fuks, and J.-M. Lehn, Chem. Eur. J. 2006, 12, 1723-1735; b) C.-F. Chow, S. Fujii, and J.-M. Lehn, Angew. Chem. Int. Ed. 2007, 46, $5007-5010$; c) S. Barik and W.G. Skene, Polym. Chem. 2011, 2, 1091-1097; d) S. Barik, and W.G. Skene, Macromolecules, 2012, 45, 1165-1173.

[19] F. Tanaka, N. Mase and C.F. Barbas, J. Am. Chem. Soc., 2004, 126, 3692-3693.

[20] P.J. Coelho, M. Cidália, R. Castro, M. Manuela, M. Raposo, J. Photochem. Photobiol., A, 2013, 259, 59-65.

[21] a) Y. Zhang and M. Barboiu, ACS Omega, 2018, 3, 329-333; b) Y. Zhang and M. Barboiu, Chem. Commun., 2015, 15, 15925-15927. 


\section{Entry for the Table of Contents}
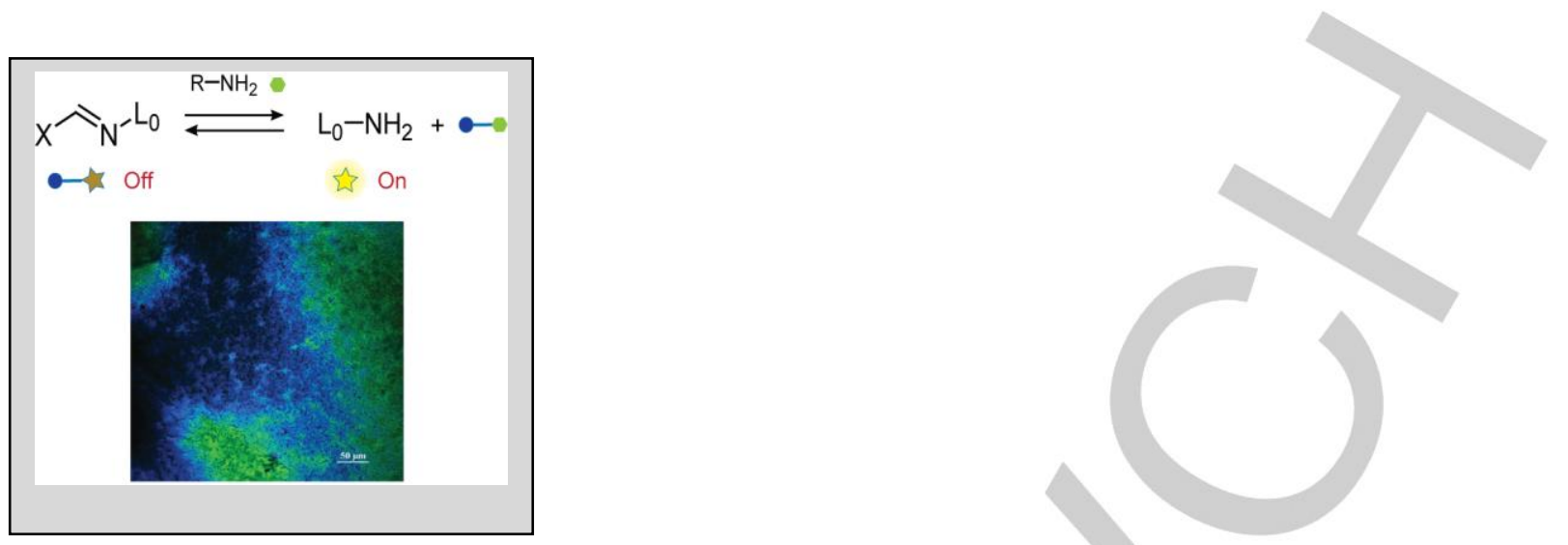

Sold films constituted of dynamic covalent fluorodynamers have been designed and used to analyse the interface imine exchange reactions between solid-solution interface, leading to re-composition and tunable fluorescence in response to competing amines and acid/base conditions. 